\title{
A flow cytometry based method for studying embryogenesis and immune reactivity to embryogenic stages in filarial parasites Bikash Ranjan Sahu1 ${ }^{1}$, Alok Das Mohapatra ${ }^{1}$, Arindam Majumder ${ }^{1}$, Pradip K Das ${ }^{2}$ and Balachandran Ravindran*1
}

Address: ${ }^{1}$ Division of Immunology, Regional Medical Research Centre, Indian Council of Medical Research, Chandrasekarpur, Bhubaneswar, 751023, India and 2Division of Microbiology, National Institute of Cholera and Enteric Diseases, Kolkata, 70000, India

Email: Bikash Ranjan Sahu - bikash_sahu@rediffmail.com; Alok Das Mohapatra - Aloklight@rediffmail.com; Arindam Majumder - marindum@rediffmail.com; Pradip K Das - dasp@cal2.vsnl.net.in; Balachandran Ravindran* - balaravi@sancharnet.in

* Corresponding author

Published: 07 November 2005

Filaria Journal 2005, 4:II doi:10.1186/1475-2883-4-II
Received: 18 April 2005

Accepted: 07 November 2005

This article is available from: http://www.filariajournal.com/content/4/I/II

(c) 2005 Sahu et al; licensee BioMed Central Ltd.

This is an Open Access article distributed under the terms of the Creative Commons Attribution License (http://creativecommons.org/licenses/by/2.0), which permits unrestricted use, distribution, and reproduction in any medium, provided the original work is properly cited.

\begin{abstract}
Background: In the absence of intermediate animal hosts, the process of embryogenesis leading to fecundity of adult female filarial worms is very critical for persistence of these obligate parasites in human communities. Embryogenesis in adult female filarial parasites involves fertilization of eggs or oocytes by sperms and their subsequent development into motile microfilariae inside the uterine cavity of worms. Development of assays for monitoring embryogenesis in adult female worms is a critical requirement in filariasis research - filarial worms are known to harbour endosymbionts such as Wolbachia which play a significant role in fecundity. Tetracycline or doxycycline treatment of the infected hosts effectively eliminates the endosymbionts resulting in inhibition of embryogenesis in female worms. Currently, inhibition of embryogenesis in adult filarial worms can be monitored only by microscopic examination of in vitro harvested intrauterine stages.
\end{abstract}

Methods: Adult female filarial worms of bovine filarial parasites, Setaria digitata were collected from the peritoneum of infected animals and intrauterine stages were harvested in culture medium and were analyzed for forward and side scatter by flowcytometry using a BD FACS Calibur. Different populations were gated, sorted and identified by phase microscopy. Binding of biotinylated lectins to intra uterine stages was monitored using FITC labeled Avidin and monitored by flow cytometry of gated populations. Similarly, binding of antibodies in human filarial sera to intrauterine stages was monitored using FITC labeled anti-human immunoglobulins.

Results: The forward and side scatter for intrauterine stages delineated 3 distinct populations labeled as RI, R2 and R3. The three populations were sorted and identified to be a) fully stretched microfilariae, b) early and c) late developmental stages of eggs respectively. Lectins such as Wheat Germ agglutinin or Concanavalin-A were found to bind strongly to egg stages and less prominently to intra-uterine microfilariae. Similarly the binding of antibodies in filarial sera to the three intra-uterine stages could also be precisely quantified.

Conclusion: The manuscript reports a novel flow cytometry based method to monitor progression of embryogenesis in adult filarial worms. Apart from relative quantification of different intra uterine developmental stages, the assay allows quantitative binding of lectins and antibodies to each of the intrauterine stages. It may now be possible to quantify levels of antibodies in infected and immune hosts to monitor anti-fecundity immunity in filariasis - the assay can thus be used as a powerful tool for drug development and in immunological studies in human and experimental filariasis. 


\section{Background}

Lymphatic filariasis causes debilitating chronic hydrocele and/or lymphoedema in about 40 million people world wide - nearly 120 million people are found infected with the nematodes, about $90 \%$ with W.bancrofti and the rest with B.malayi, mostly in tropical countries. Infective larvae (L3) from mosquitoes enter the mammalian host and develop into male and female adult stage parasites in the lymphatics. After mating the adult female worms release thousands of microfilariae (Mf) that enter the blood circulation for further development in mosquitoes. In the absence of intermediate animal hosts, the process of embryogenesis leading to fecundity of adult female worms is very critical for persistence of these obligate parasites in human communities.

Morphologically, different intrauterine developmental stages are discernable in the uterine cavity of adult female worms. Eggs or oocytes after fertilization with sperms transform into motile microfilariae and are released by the adult female worms [1]. Currently, tools are not available to quantify the different developmental stages of embryogenesis other than approximate scoring by microscopy $[2,3]$. Development of precise assays for monitoring embryogenesis in adult female worms have the potential to address crucial issues in filariasis research - filarial worms are known to harbour endosymbionts such as Wolbachia, which play a significant role in fecundity of adult filarial worms $[3,4]$. Tetracycline or doxycycline treatment of the infected hosts effectively eliminates the endosymbionts resulting in inhibition of embryogenesis in female worms [5]. Inhibition of embryogenesis in infected human hosts can be scored only by monitoring decrease/ loss of peripheral microfilaraemia-lymphatic dwelling adult stage parasites are not accessible for study. However in experimental animal models the adult female worms can be harvested and dissected in vitro and the intrauterine stages can be approximately scored by microscopy $[2,3]$. In this communication we describe a flow cytometry based method for studying embryogenesis in adult female filarial worms. The utility of this method for quantifying binding of lectins and antibodies to different intra uterine stages of filarial parasites has also been evaluated.

\section{Methods}

\section{Preparation of intra-uterine stages for flow cytometry}

Adult female filarial worms, Setaria digitata were collected from the peritoneum of cattle at a nearby abattoir in sterile alpha - MEM containing 1\% glucose, Penicillin-100 units $/ \mathrm{ml}$, Streptomycin-100 $\mu \mathrm{g} / \mathrm{ml}$ Gentamycin-50 $\mu \mathrm{g} / \mathrm{ml}$ and Amphotericin-B $2.5 \mu \mathrm{g} / \mathrm{ml}$ and transported to the laboratory and used on the same day. Individual worms taken in a petridish were washed three times (x3) in sterile medium and dissected into small pieces in about $5 \mathrm{ml}$ of medium and incubated at $37^{\circ} \mathrm{C}$ for 30 mins. The large pieces were removed and the medium containing intrauterine stages were harvested, washed in MEM and the final pellet of cells suspended in $1 \mathrm{ml}$ of sheath fluid and analyzed using a flowcytometer (FACSCalibur, Becton Dickinson, USA) using Cell Quest Pro software. The data (5000 events) were acquired for forward and side scatter using the following settings: FSC, voltage E00 and SSC, voltage 340 . The three populations were gated and sorted using a FACS sorter under moderate fidelity settings. The sorted suspensions were centrifuged on to microscopic slides using a cytospin and observed under a phase contrast microscope for identification of organisms in the gated populations.

\section{Collection of blood for sera from human filariasis cases}

Blood for sera were collected from patients with chronic filariasis (elephantiasis/hydrocoele) and microfilariae carriers from filariasis endemic areas near Bhubaneswar as described by us earlier [6]. Sera stored at $-20^{\circ} \mathrm{C}$ were diluted in PBS with $1 \%$ BSA and used for binding to intrauterine stages as described above.

\section{Preparation of immune sera against intrauterine stages}

Five Mastomys coucha were immunized with three doses (15 days apart) of intra-uterine stages (50,000 cells per dose) in complete Freund's adjuvant and blood for sera was collected between days 40-45 and tested for antibody reactivity to intrauterine stages as described above.

\section{Purification of circulating microfilariae from infected blood}

Microfilariae (Mf) from human blood were purified using $5 \mu \mathrm{M}$ pore polycarbonate membranes as described by us earlier [6]. Nocturnal blood samples collected from W.bancrofti infected Mf carriers or day time blood samples from S.digitata infected cattle were used for purification - Mf washed in Tris-EDTA buffer were taken in sheath fluid and analyzed by flow cytometry for forward and side scatter as described above.

\section{Lectin binding assay}

A suspension $(500 \mu \mathrm{l})$ containing about 10,000 intra uterine stages in PBS 7.2 with $1 \%$ BSA were mixed with $500 \mu \mathrm{l}$ of $4 \mu \mathrm{g} / \mathrm{ml}$ or $1 \mu \mathrm{g} / \mathrm{ml}$ of biotinylated WGA (L-5142, Sigma Chemical Co, USA). Simlarly two dilutions, 500 or 2000 fold diluted biotinylated Con-A (BA-16, Bangalore Genie, India) were used and the suspensions were incubated at RT for $45 \mathrm{~min}$. The cells were then washed $\mathrm{x} 3$ in PBS and taken in $0.5 \mathrm{ml}$ of PBS with 1\% BSA to which 0.5 ml of 250 fold diluted Avidin - FITC (S-3762, Sigma Chemical Co, USA) was added and incubated for $30 \mathrm{~min}$ at RT. The suspension was washed again thrice in PBS and samples taken in $1 \mathrm{ml}$ of sheath fluid and 5000 events were acquired. The three populations were gated and fluorescence intensity was read using a $488 \mathrm{~nm}$ laser. The 


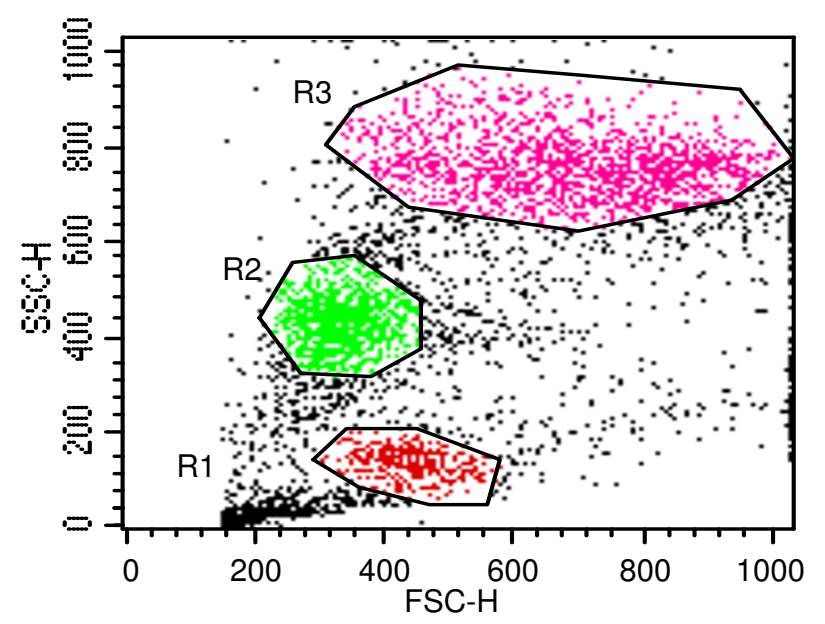

(a)

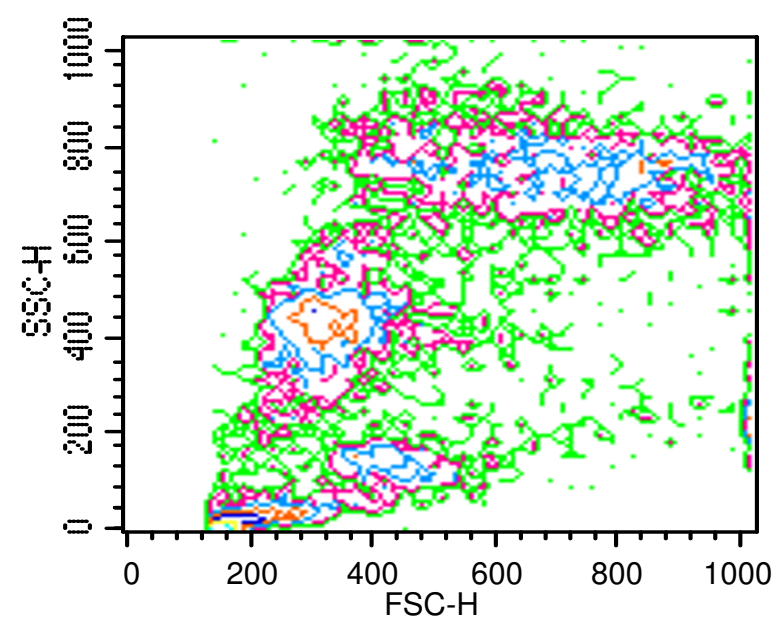

(b)

Gated events in R1-351

R2-1008

R3-1597

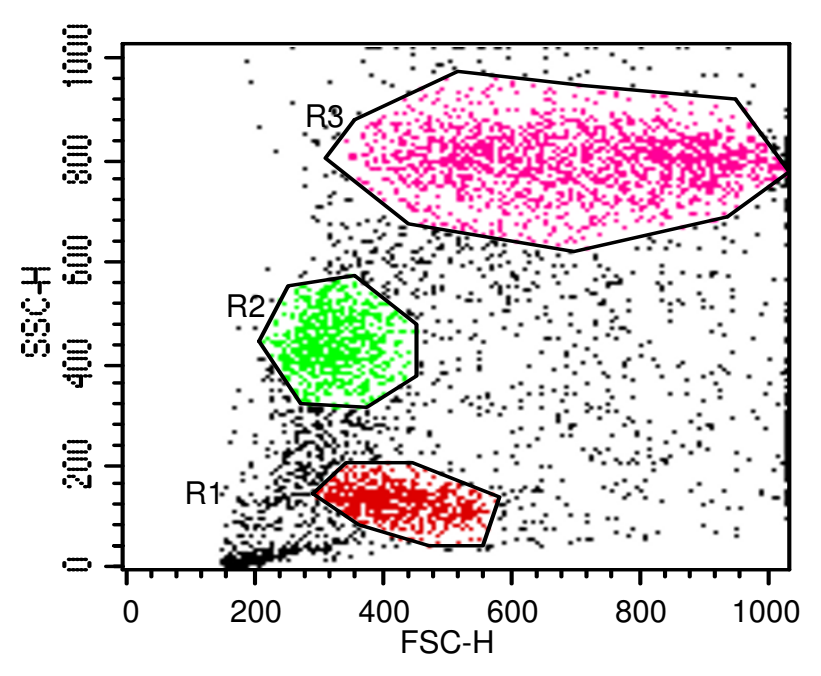

(c)

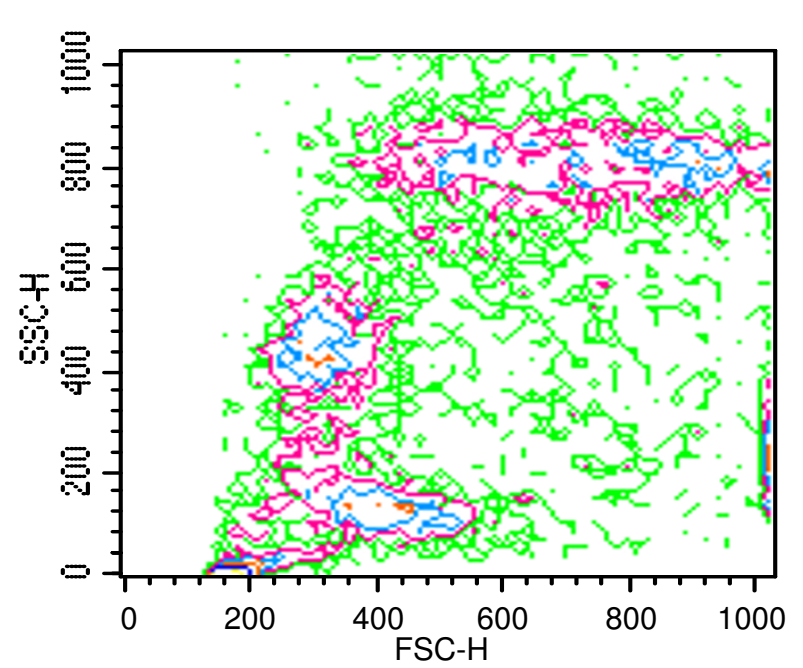

(d)

\section{Gated events in R1-630 \\ $\mathrm{R} 2-773$ \\ R3-1776}

\section{Figure I}

Three populations RI, R2 and R3 in forward (FSC, voltage E00) and side scatter (SSC, voltage 340) of intra-uterine stages; two representative worms by Flow cytometry are shown: I a and Ic - Dot plots; I b and Id - respective contour maps; the number of events in individual gates for IU stages are indicated below respective figures. 


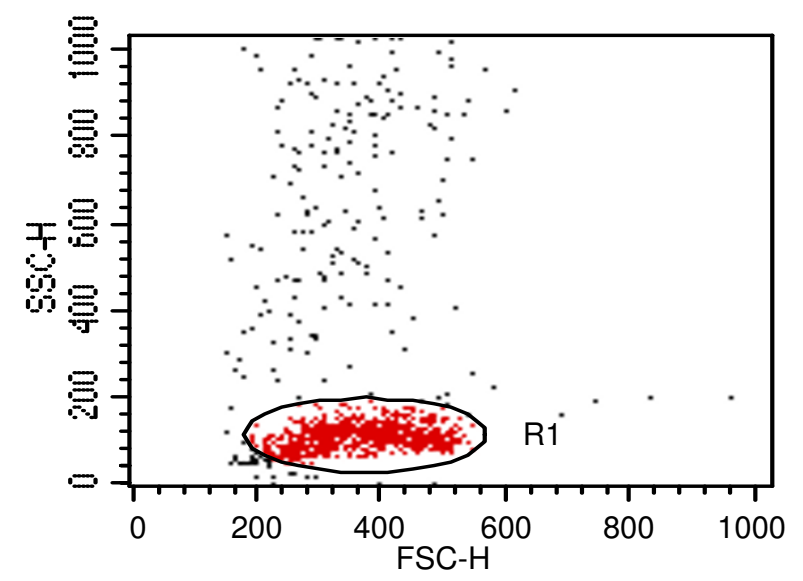

(a)

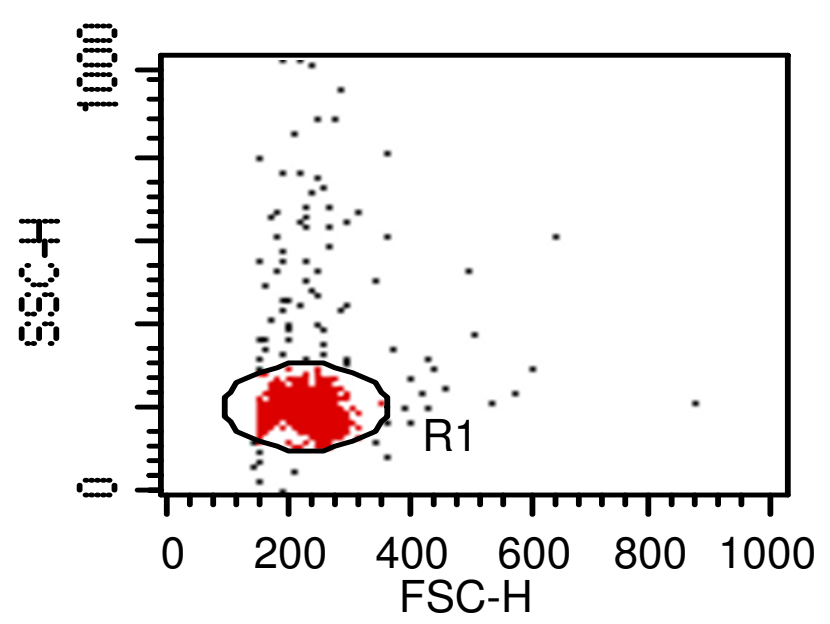

(b)

Figure 2

Dot plots for purified Mf of S.digitata (2a) and W.bancrofti

(2b) in forward and side scatter.

percentage reactivity of lectins in comparison to AvidinFITC controls was calculated using CellQuest Pro software.

\section{Antibody binding assay}

A suspension $(500 \mu \mathrm{l})$ containing about 10,000 IU stages in PBS-BSA were mixed with $500 \mu \mathrm{l}$ of 50 fold diluted human or Mastomys sera (normal as well as immunized animals) and incubated at RT for $45 \mathrm{~min}$. The cells were then washed $\mathrm{x} 3$ and taken in $0.5 \mathrm{ml}$ of PBS-BSA to which $0.5 \mathrm{ml}$ of 250 fold diluted FITC labeled anti-human Immunoglobulin (F-6506, Sigma Chemical Co.USA) or
50 fold diluted FITC labeled anti-mouse IgG was added and incubated for $30 \mathrm{~min}$ at RT. The suspension was washed $\mathrm{x} 3$ in PBS and organisms were taken in $1 \mathrm{ml}$ of sheath fluid for acquiring 5000 events in FACS Calibur. The three populations were gated and fluorescence intensity was read using a $488 \mathrm{~nm}$ laser. The percentage reactivity as well as mean fluorescence intensity were calculated for antibody binding and compared with FITC labeled second antibody conjugate controls using CellQuest Pro software.

\section{Results}

\section{Forward and Side scatter and identity of stages}

Figs 1a \&1c show the dot plots of intrauterine stages in forward and side scatter for two representative adult worms; respective contour maps are shown in Fig $1 \mathrm{~b} \& 1 \mathrm{~d}$. Three distinct populations of organisms, R1, R2, and R3 could be identified. The three populations were consistently found in several worms although the relative numbers in each scatter varied between worms as shown in Fig 1. Purified $\mathrm{mf}$ of S.digitata and W.bancrofti (from blood) by using nucleopore membrane filtration scattered exclusively in the $\mathrm{R} 1$ region indicating that organisms in this region are microfilariae (Fig $2 \mathrm{a}$ and $2 \mathrm{~b}$ respectively). The organisms in the three scatter groups were purified by sorting them in a FACS Calibur sorter and examined under a phase contrast microscope: Figs 10 \&11 show organisms in the unsorted population which contain a mixture of early and late developmental stages of eggs as well as fully stretched Mf, while Fig 12 and 13 reveal pure Mf of S.digitata in the sorted R1 population confirming the data presented in fig $2 \mathrm{a}$ and $2 \mathrm{~b}$ above. Organisms in R2 gate were found to be early developmental stages of eggs (Fig 8) while late developmental stages were found in the R3 population (Fig 9).

\section{Lectin binding to intra-uterine stages}

Two lectins, Wheat Germ Agglutinin (WGA) and Conconavalin-A (Con-A) that specifically react primarily with $\mathrm{N}$ Acetyl-D-Glucosamine and D-mannose residues respectively (which are present ubiquitously in several parasites including filarial parasites), were chosen as markers in this study to evaluate the flow cytometry based assay procedure. The intrauterine stages incubated with biotinylated WGA or Con-A were analysed for single colour fluorescence using $488 \mathrm{~nm}$ laser in the three gated population. The background reactivity and mean fluorescence reactivity of avidin-FITC (controls) for the three gated populations was minimal. The specific binding of WGA to the three populations is shown in Fig $7 \mathrm{a}-\mathrm{f}$. There was a dose dependant binding of WGA to intra-uterine stages lower concentrations Fig 7d,e \&7f) bound proportionately less than higher concentrations as shown in histograms in Fig (7a,b \&7c). Similarly a dose dependent binding of Con-A to intrauterine stages could also be 


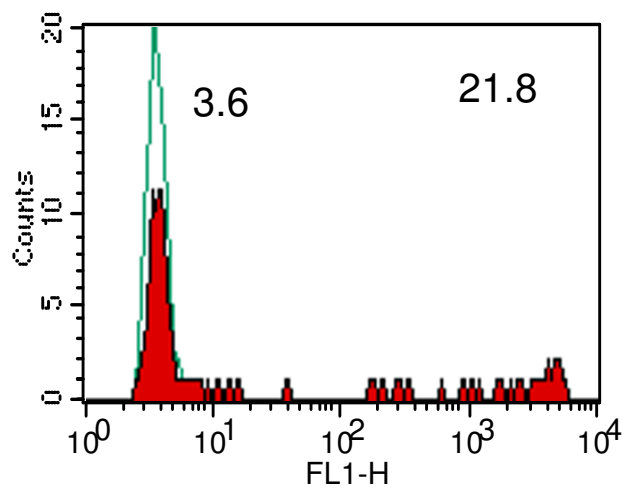

(a)

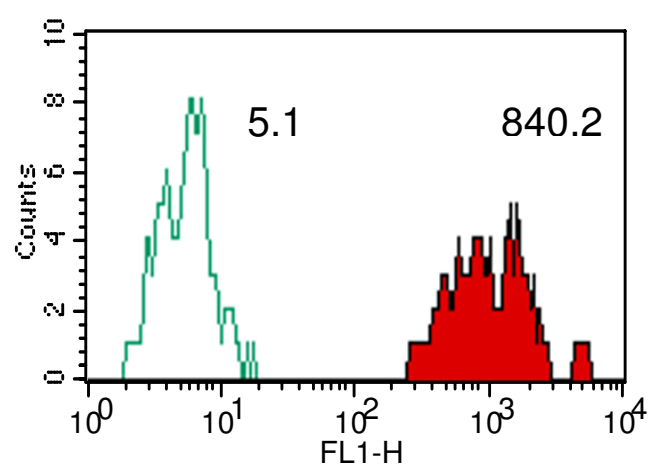

(b)

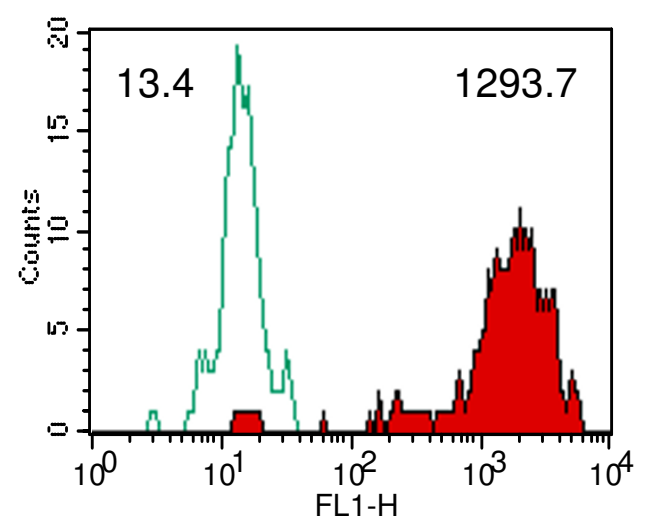

(c)

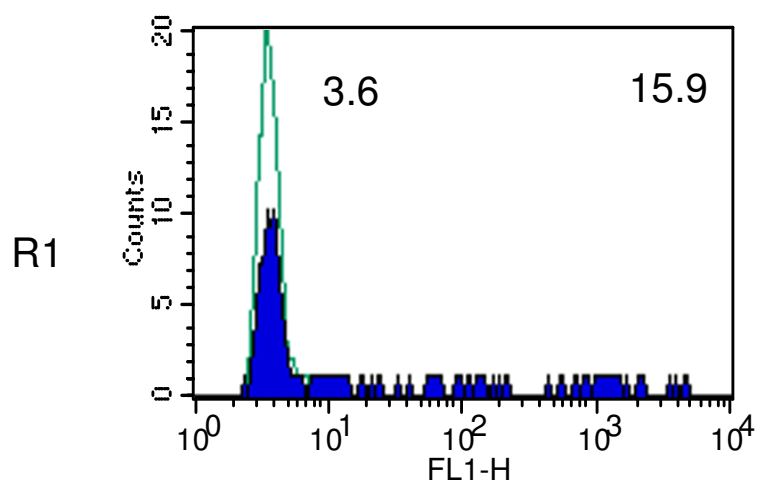

(d)

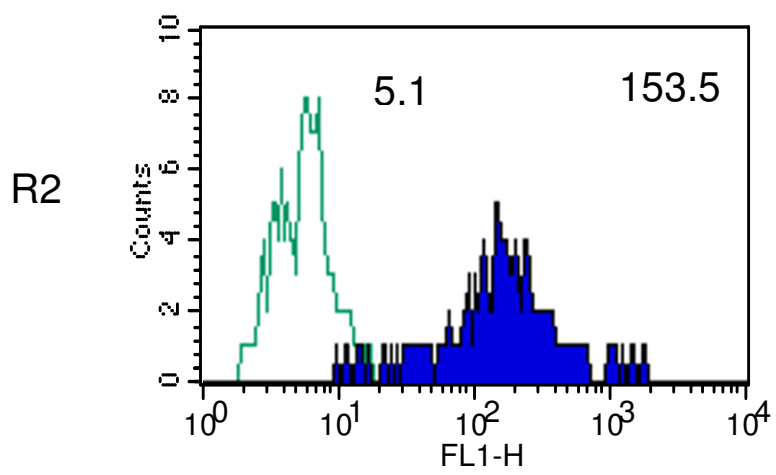

(e)

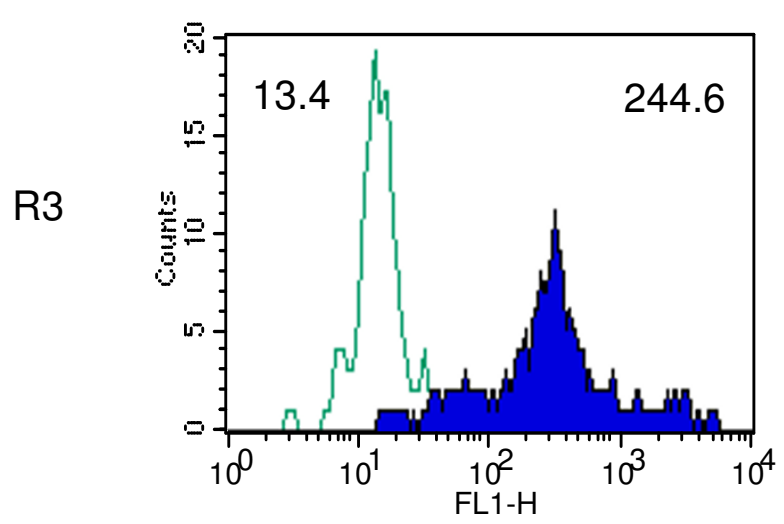

(f)

Figure 3

Con-A binding to intra-uterine stages: single colour analysis using $488 \mathrm{~nm}$ laser; 3 a,b and c: Con-A (500 fold diluted) reactivity to RI,R2 and R3 gated populations. 3 d, e and f: Con-A (2000 fold diluted) reactivity to RI, R2 and R3 gated populations. Green line: Avidin-FITC control; coloured shaded areas: specific reactivity of Con-A. Numbers shown on top left and top right on histograms represent geometric mean intensity of fluorescence for control and Con-A respectively. 


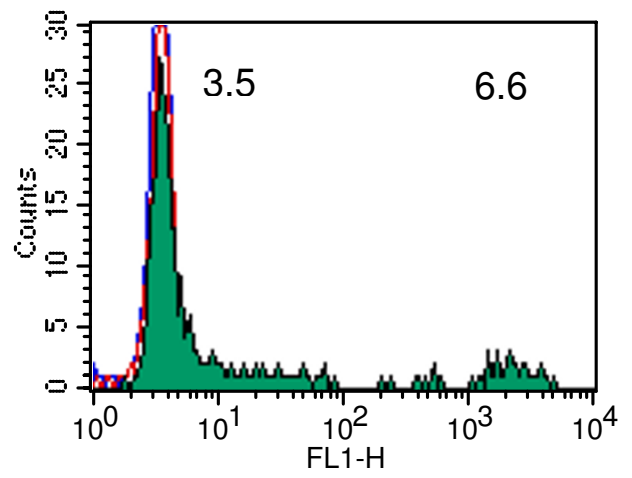

(a)

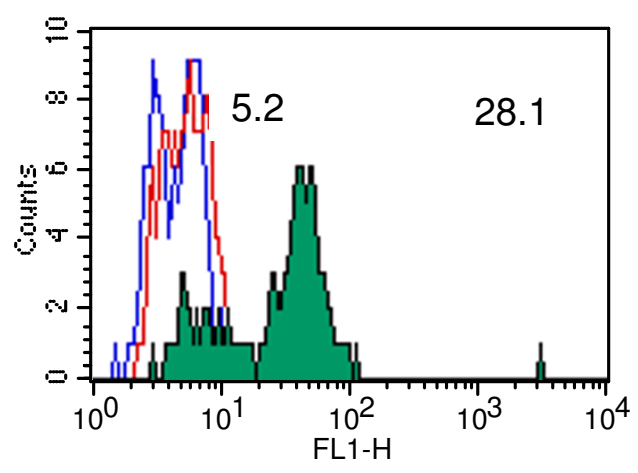

(b)

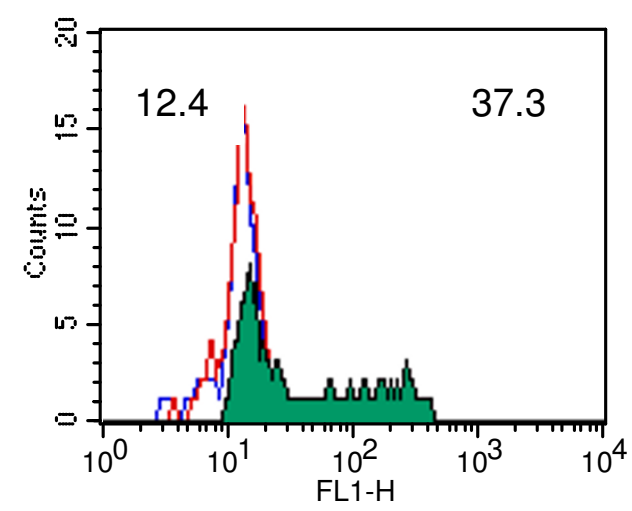

(c)

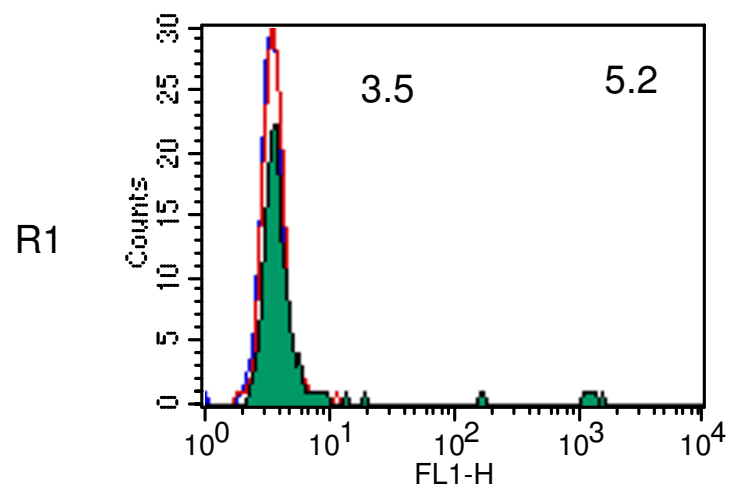

(d)

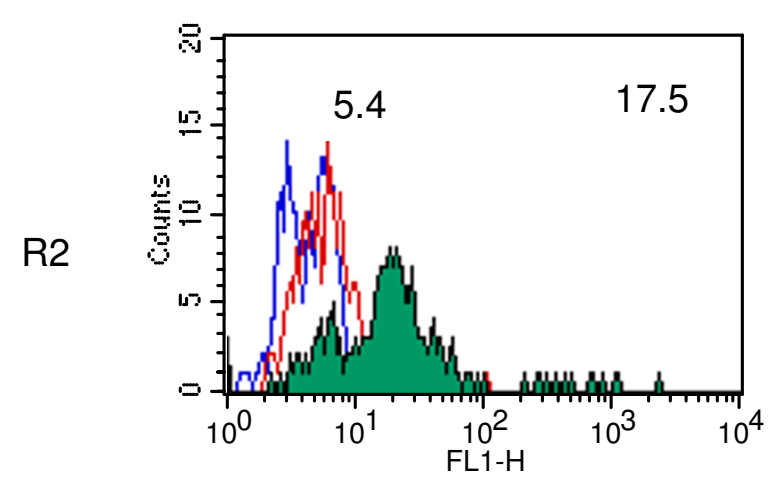

(e )

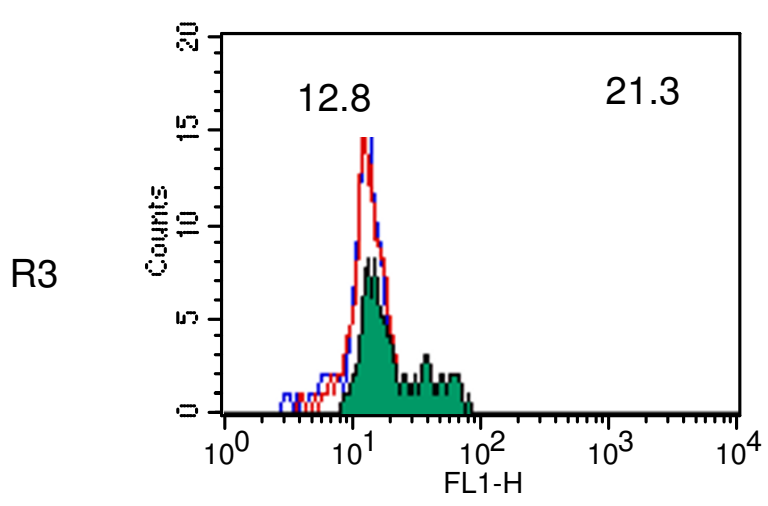

(f)

\section{Figure 4}

Antibodies binding in sera of M.coucha to three gated populations (RI,R2 and R3) of intra-uterine stages. Fig 4 a,b and c for one animal and Fig $\mathbf{4} \mathbf{d}, \mathbf{e}$ and $\mathbf{f}$ for a second animal are shown in the histogram. Blue lines: Anti-mouse IgG-FITC conjugate control; red lines: Pre-immune sera; Coloured shaded areas: antibody reactivity in respectiveimmunized sera. Numbers shown on top left and top right on histograms represent geometric mean intensity of fluorescence for pre and post-immunized sera respectively. 


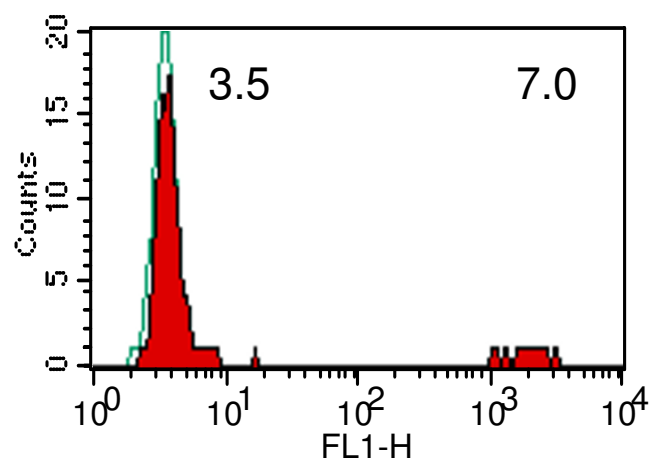

( a )

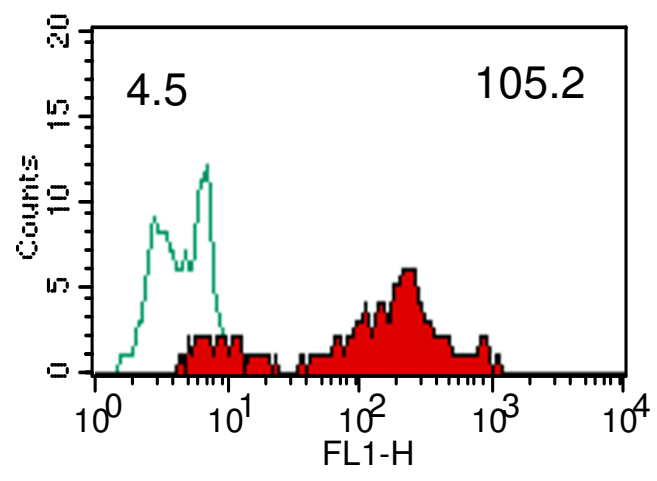

(b)

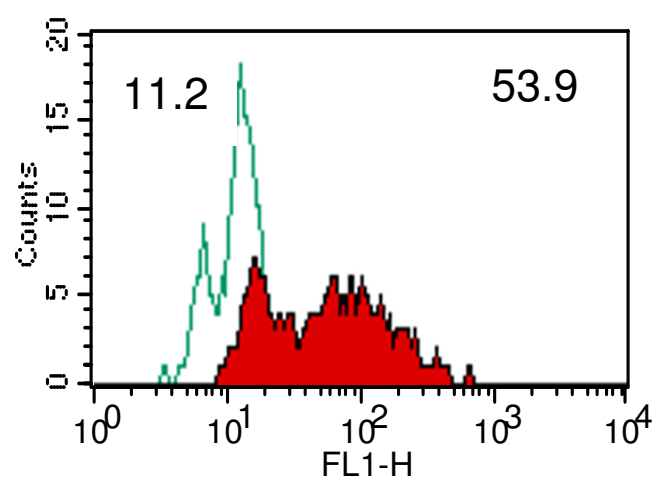

(c)

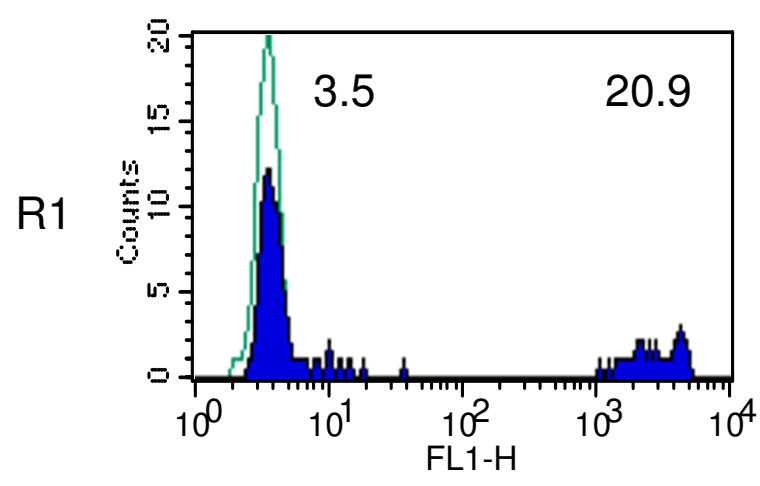

(d)

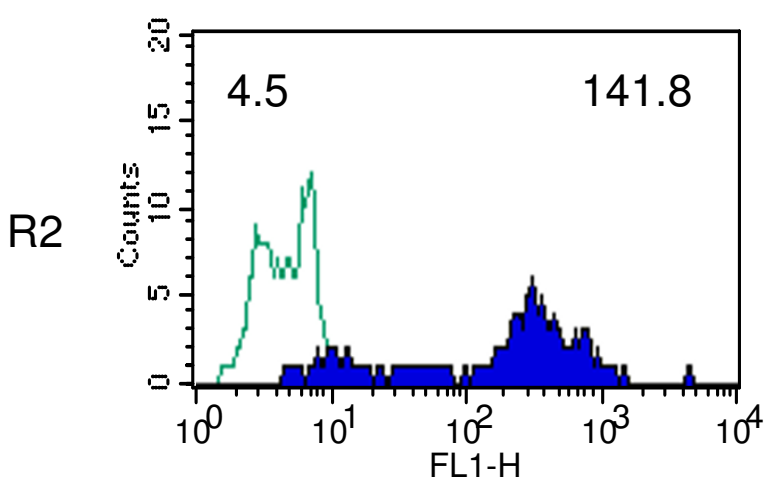

( e )

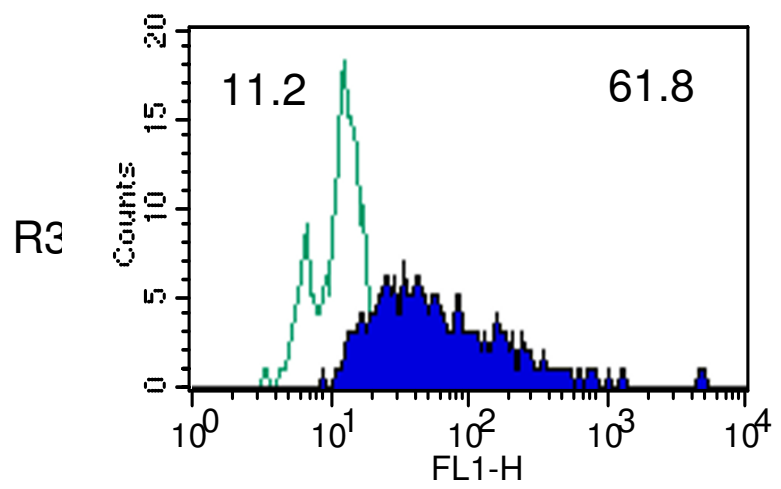

( f )

\section{Figure 5}

Antibody binding in two patients with chronic filariasis: Histograms showing reactivity to the three gated populations (RI,R2 and R3) of intra-uterine stages. Fig $\mathbf{5}$ a,b and $\mathbf{c}$ for one human serum and Fig $\mathbf{5}$ d,e and $\mathbf{f}$ for another patient. Blue line: Antihuman IgG-FITC control; Colour shaded areas: Antibody reactivity in test sera; Numbers shown on top left and top right on histograms represent geometric mean intensity of fluorescence for control and test sample respectively. 


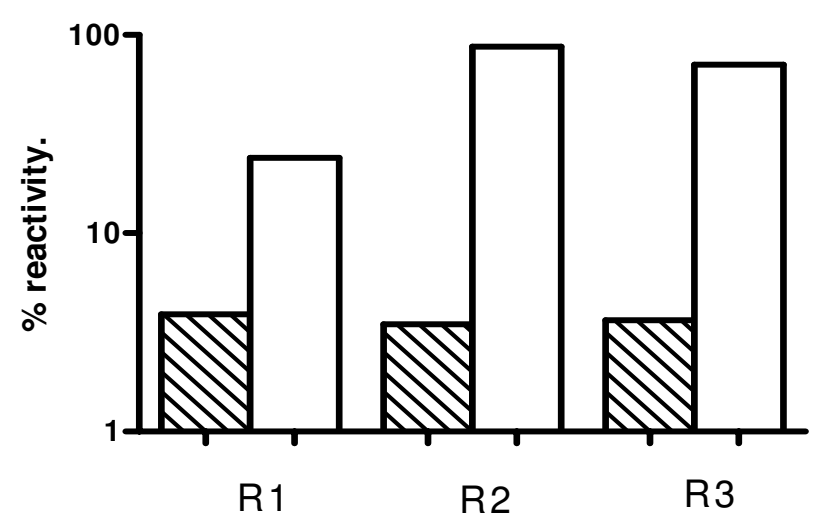

(a)

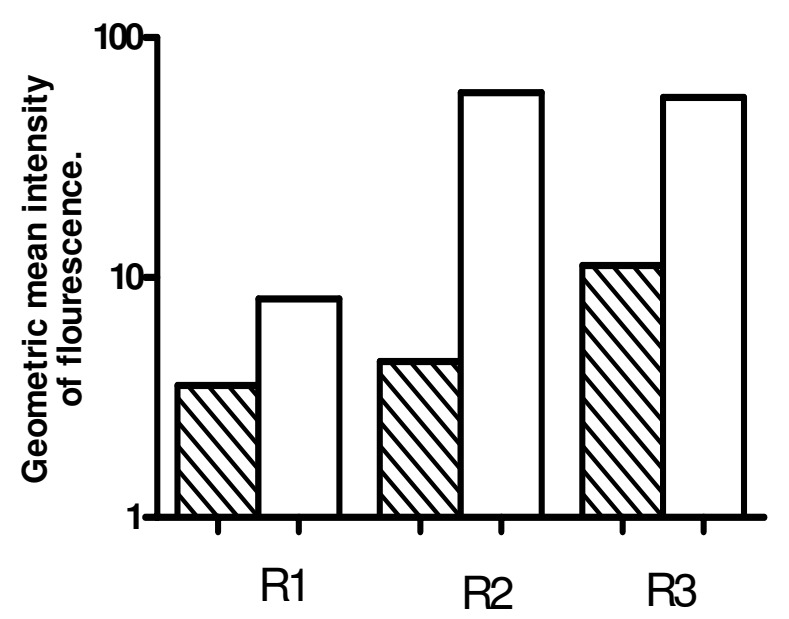

(b)

\section{Figure 6}

Antibody binding in chronic filariasis cases; Fig 6 (a): Mean percentage reactivity of antibodies in nine subjects to different intra-uterine stages. Fig 6 (b): Mean Geometric fluorescent intensity for the same sera depicted in $\mathbf{6 a}$. Striped bars: Anti-human IgG-FITC conjugate control; Open bars: test samples.

demonstrated (Fig 3a-f). Both the lectins bound significantly (>95\%) to early and late developmental stages of eggs (R2 and R3 respectively) - their reactivity to intrauterine Mf (R1) was, however, not high.

\section{Antibody binding to Intra-uterine stages}

The binding of antibodies in human Bancroftian filariasis and in S.digitata immune Mastomys sera to intrauterine developmental stages could also be studied. The results of single colour fluorescence using $488 \mathrm{~nm}$ laser in the threegated populations in two Mastomys sera are shown in Fig 4. The background binding of anti-mouse IgG-FITC conjugate to the three gated populations R1, R2, and R3 was very minimal. The binding profile of pre-immune sera were similar to conjugate controls while significant binding of antibodies to intrauterine eggs (R2 and R3 populations) could be demonstrated in both the immune sera (Fig 4a-f), in addition, similar reactivity was shown in three other immune Mastomys sera also (data not shown). Binding of antibodies in human filariasis sera to intrauterine stages could also be shown by the assay. The assay for two sera of elephantiasis cases is shown in Fig $5 \mathrm{a}-\mathrm{f}$. Significant binding of antibodies to intrauterine stages, particularly to egg stages could be demonstrated.

Although antibodies in human sera did not bind well to intra-uterine Mf, very significant binding of antibodies to a small select population of Mf was demonstrable by the assay (Fig 5a \&5d). The mean antibody levels in nine patients with chronic filariasis were quantified (Fig 6). The levels were expressed as percentage reactivity and mean geometric fluorescence intensity as shown in Fig $6 a$ \&6b respectively. The antibody and lectin binding reported in this study are primarily restricted to reactivity of these molecules to the surface of intra-uterine stages since fresh live stages collected from adult female worms were used for the assays. Fixation with formaldehyde and permeabilising the cells resulted in antibody binding to intracellular components also (data not shown).

\section{Discussion}

Embryogenesis is central to the biology of helminths and could be an effective target for devising intervention strategies for blocking transmission of parasitic helminths from mammalian hosts. Immunological studies in human as well as experimental filariasis have been largely directed towards host responses against infective larvae, microfilariae and adult stage parasites [7,8]. However, very few studies have addressed antigens expressed in/on intrauterine developing stage [9]. We consider the nonavailability of sensitive assays to undertake studies on antibody responses to intrauterine stages as one of the reasons for such a limited number of studies. The large size of intrauterine stages (about $50 \mu \mathrm{M}$ for egg stages and about $160 \mu \mathrm{M}$ for Mf) do not limit the applicability of this novel assay since no special modification in the flowcytometer is required, the dimensions of standard flowcell provided by the manufacturers in FACSCalibur model was sufficient to perform the assays. We envisage a wide application for this new flowcytometry-based method of monitoring embryogenesis as well as antibody binding to intra-uterine stages in filariasis research: a) removal of endosymbionts in human hosts by doxycycline requires 


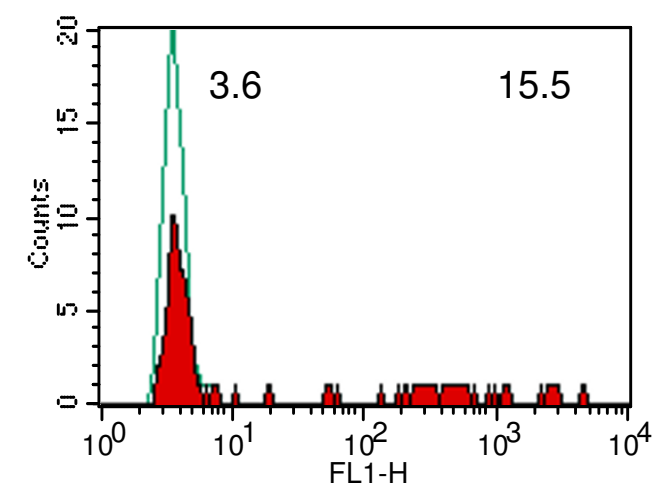

(a)

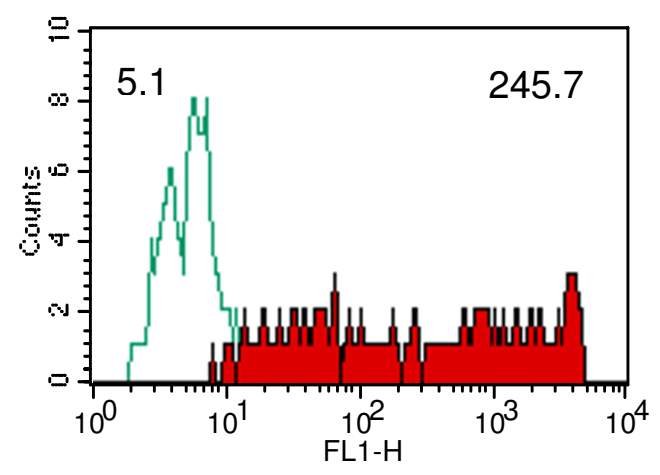

(b)

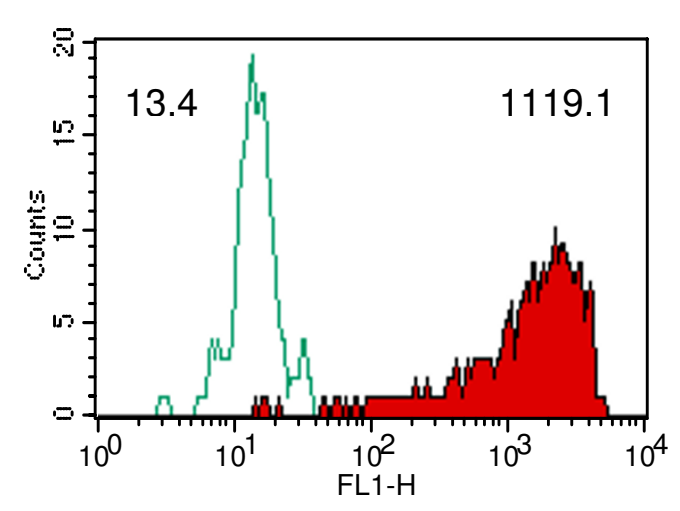

(c)

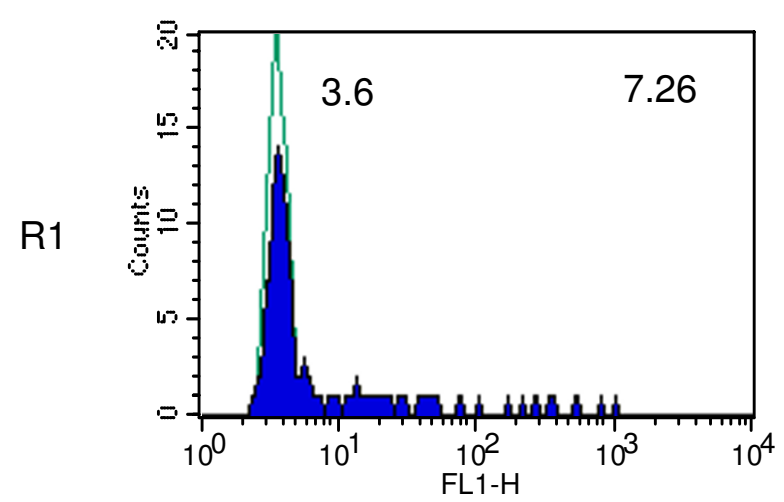

(d)

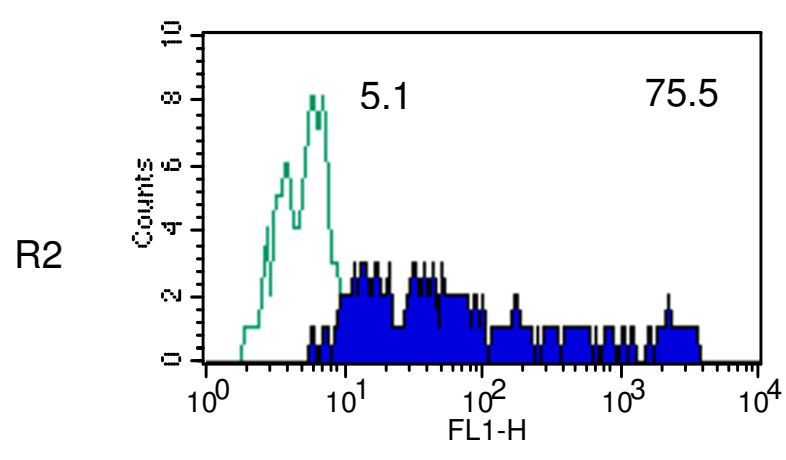

(e )

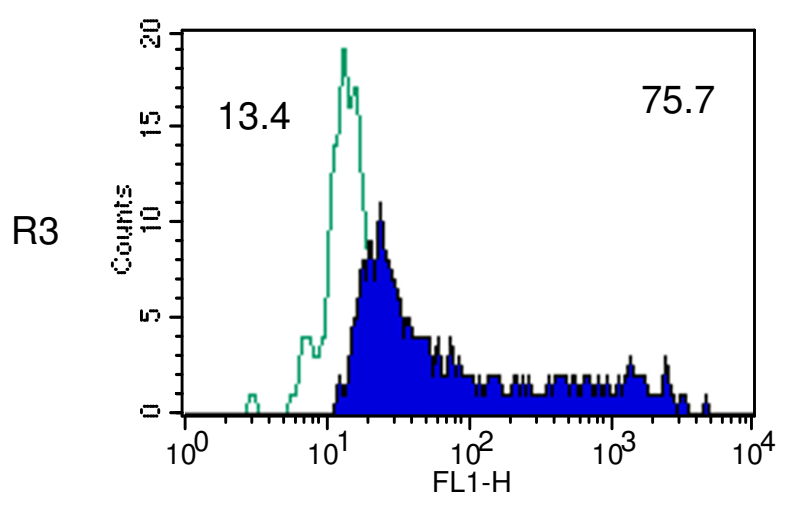

(f)

\section{Figure 7}

Binding of WGA to intra-uterine stages: single parameter analysis using $488 \mathrm{~nm}$ laser; 7 a,b and c: WGA (2 $\mu \mathrm{g} / \mathrm{ml})$ reactivity to RI,R2 and R3 gated populations. 7 d,e and f: WGA $(0.5 \mu \mathrm{g} / \mathrm{ml})$ reactivity to RI,R2 and R3 gated populations. Green line: Avidin-FITC control; coloured shaded areas show specific reactivity of WGA. Numbers shown on top left and top right on histograms represent geometric mean intensity of fluorescence for control and WGA respectively 


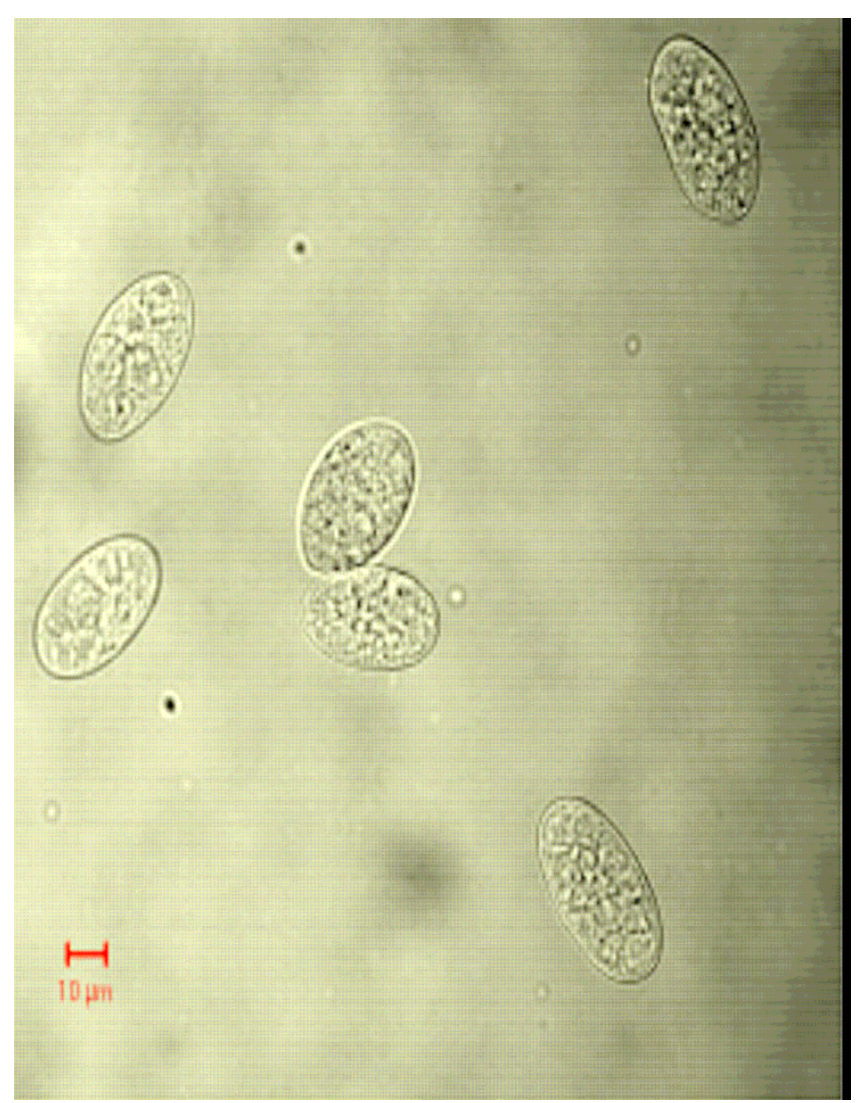

Figure 8

Sorted R2 population showing early developmental stages of eggs.

administration of the drug over a period of several weeks (5) and there is a need for developing newer anti-rickettsial drugs for blocking embryogenesis/fecundity in adult filarial worms; the new method described in this communication can be effectively used for screening a large number of potential compounds/drugs; b) although doxycycline and tetracycline have been demonstrated to eliminate endosymbionts in adult filarial worms, the precise intrauterine stage at which embryogenesis is blocked is not known and can now be studied with this new assay; c) cytokines such as IL- 4 and molecules of innate immunity such as TLR-4 have been demonstrated to play a role in regulating production of microfilaraemia in experimental hosts $[4,10]$. Adult filarial worms can now be implanted in mice made deficient for specific cytokine gene expression or transgenic for such host molecules to monitor their role in embryogenesis; d) several filarial antigens have been cloned, sequenced and expressed in recent years and some have been used as putative vaccine candidates in experimental models [11]; e) high reactivity of

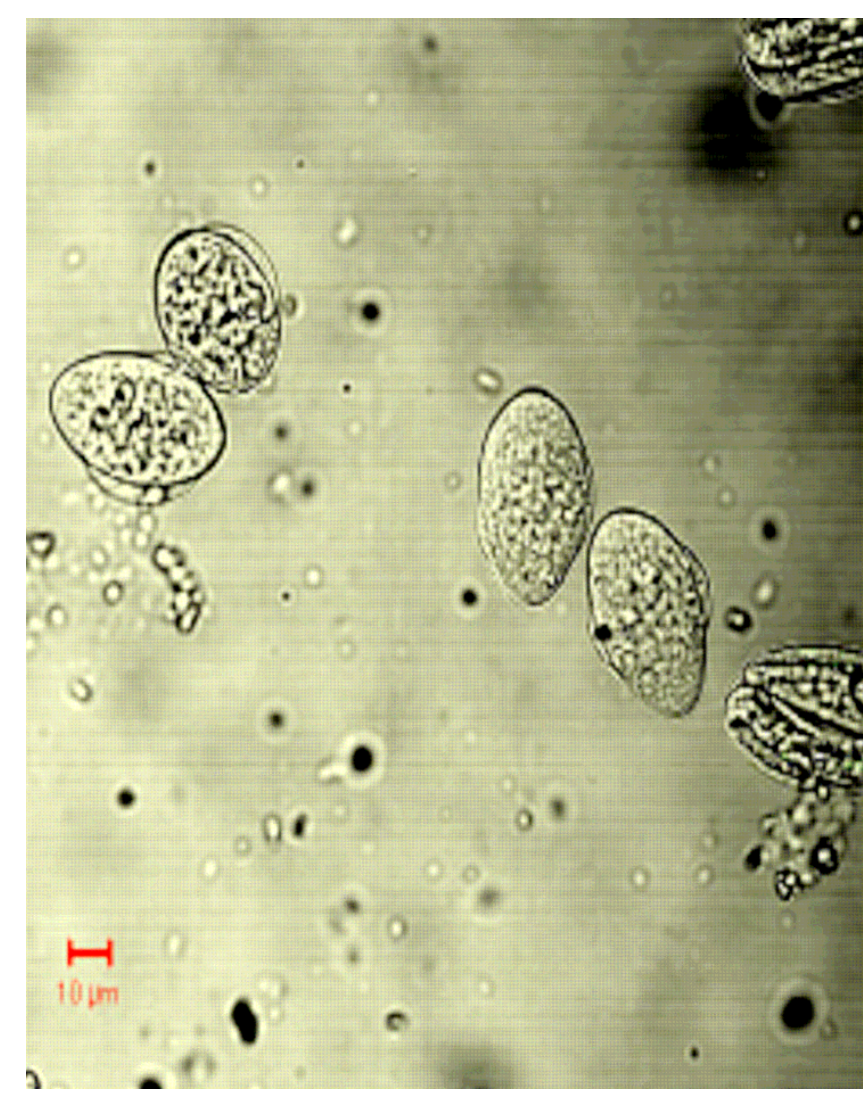

Figure 9

Sorted R3 cells of late developmental stages of eggs.

antibodies in human filariasis sera to a select population of Mf (Fig 5a \&5b) could be due to polymorphic antigens expressed on Mf sheath described by us several years ago (12). The novel procedure described here could assist in selectively sorting such reactive population of $\mathrm{Mf}$ for genetic analysis of polymorphic filarial antigens. The effect of induction of immune response to such recombinant molecules on embryogenesis can be studied using the assay described in this communication; e) filariasis in human communities presents with a variety of clinical and parasitological features. Infection is characterized by presence of circulating Mf and/or antigenemia and diseased subjects display acute and/or chronic clinical manifestations. Studies on immune responses of these patients to different developmental stages viz., infective larvae, adult stage parasite and Mf have indicated significant differences between the groups [summarized in [7]]. The new assay reported in this communication can be expected to now allow quantification of antibody responses to different intra-uterine stages of filarial para- 


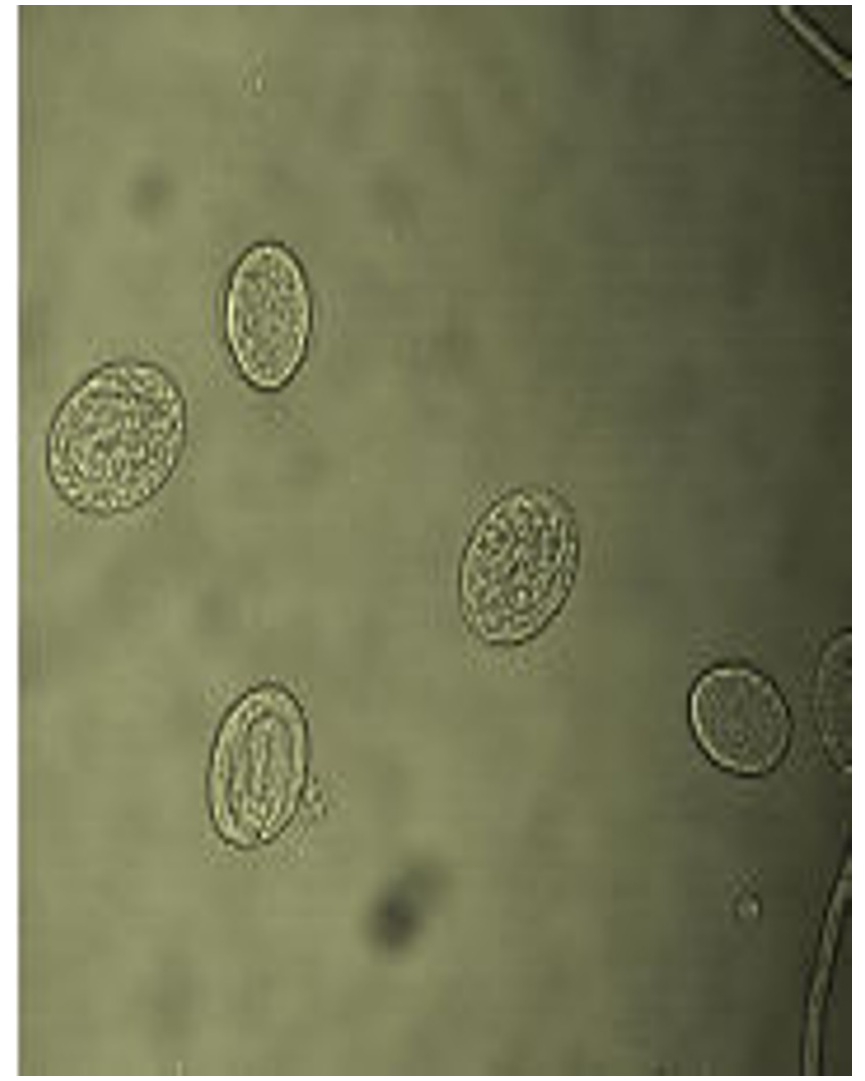

\section{Figure 10}

Phase contrast microscopic image of unsorted population of intrauterine stages. sites in human filariasis. The principles of flow cytometry have been recently used for separation and monitoring death/survival of another nematode C.elegans [13]. It may now be possible to study programmed cell death of developing intra-uterine stages in filarial parasites.

A bovine filarial parasite S.digitata has been used for establishment of the new assay system in this study. The assay could also be used for microfilariae of W.bancrofti (purified from infected endemic subjects). It is however, essential to evaluate the utility of this flowcytometry based method for other more commonly used filarial parasites, viz., Brugia malayi, Brugia pahangi, Dirofilaria immitis, Litomosoides sigmodontis etc.

\section{Conclusion}

The manuscript reports a novel flow cytometry based method to monitor progression of embryogenesis in adult filarial worms. Apart from relative quantification of differ-

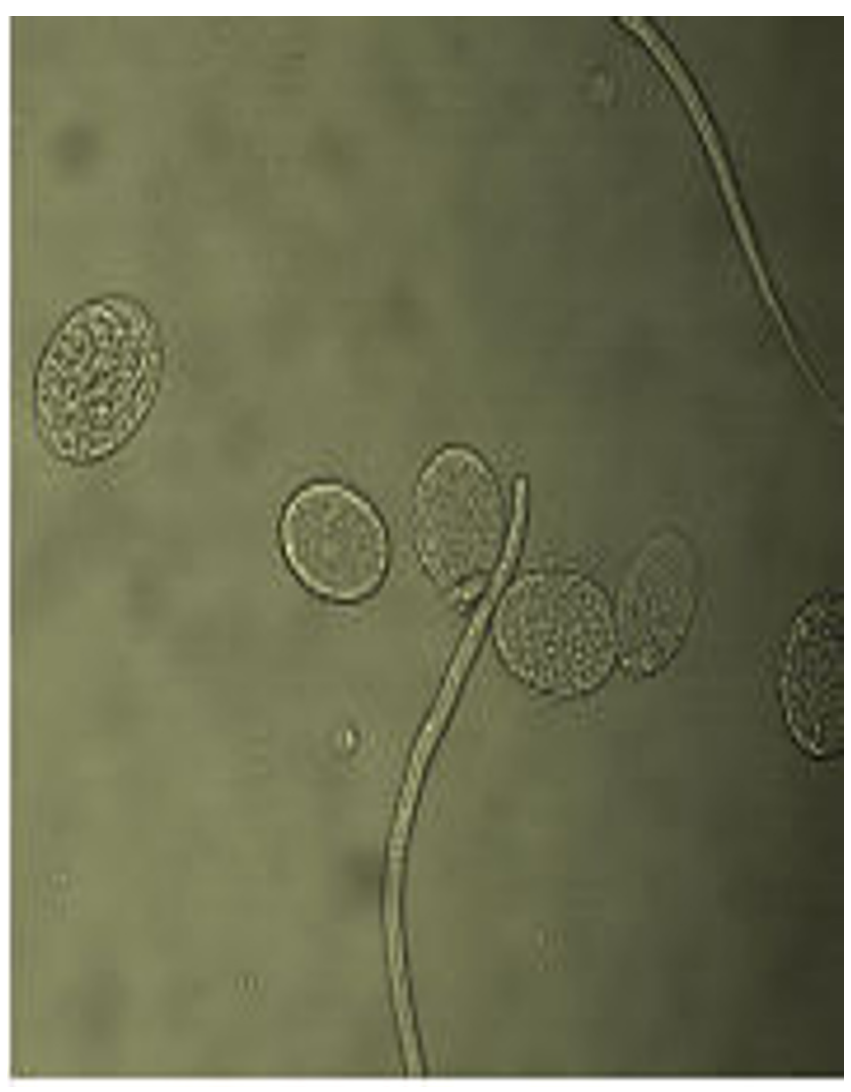

\section{Figure I I}

Phase contrast microscopic image of unsorted population of intrauterine stages.

ent intra uterine developmental stages, the assay allows quantitative binding of lectins and antibodies to each of the intrauterine stages. It may now be possible to monitor levels of antibodies in infected as well as immune hosts to intra-uterine developmental stages that could become a parameter for monitoring anti-fecundity immunity in filariasis, the assay can therefore be used as a powerful tool for drug development and in immunological studies in human and experimental filariasis.

\section{Competing interests}

The author(s) declare that they have no competing interests.

\section{Authors' contributions}

BRS: Conducted significant part of the experimental work including the assays using flowcytometer, compiled the data and wrote the draft manuscript. 


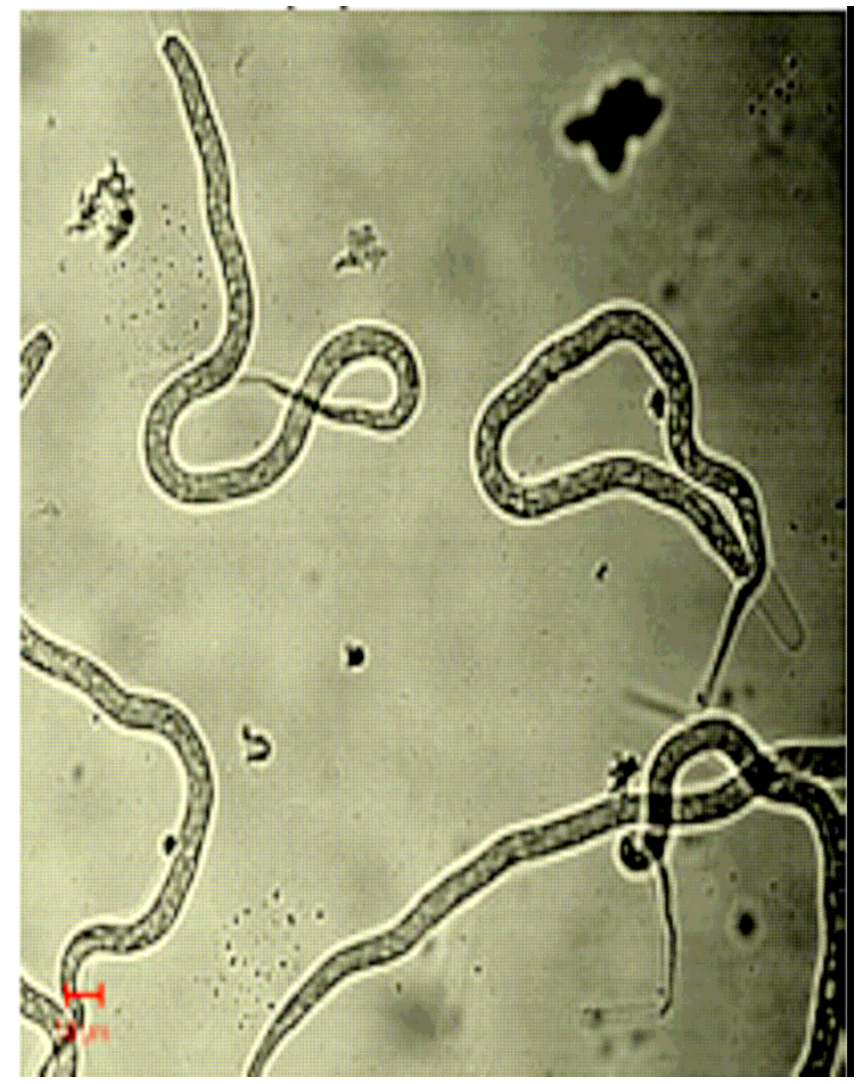

Figure 12

Sorted RI cells showing pure Mf.

ADM: Conducted part of the experimental work including the assays using flowcytometer, performed the immunoassays.

AM: Purified the stages using the sorter of flowcytometer, performed cytospin and captured phase contrast images for the sorted population.

PKD: Participated in experiments involving the use the flowcytometer sorter and use of confocal/ phase contrast microscopy

BR: Conceived the idea, designed experiments, interpreted the data and completed the manuscript

\section{Acknowledgements}

The Regional Medical Research Centre, Bhubaneswar is supported by grants from the Indian Council of Medical Research, New Delhi. The authors thank Prof. Rick Maizels, University of Edinburgh, UK for critically reading the manuscript. BRS is supported by an Indo-German grant of ICMR and ADM is supported with a Junior Research Fellowship from University Grants Commission, New Delhi. The authors thank the Director of the center, Dr.S.K.Kar for sustained support.

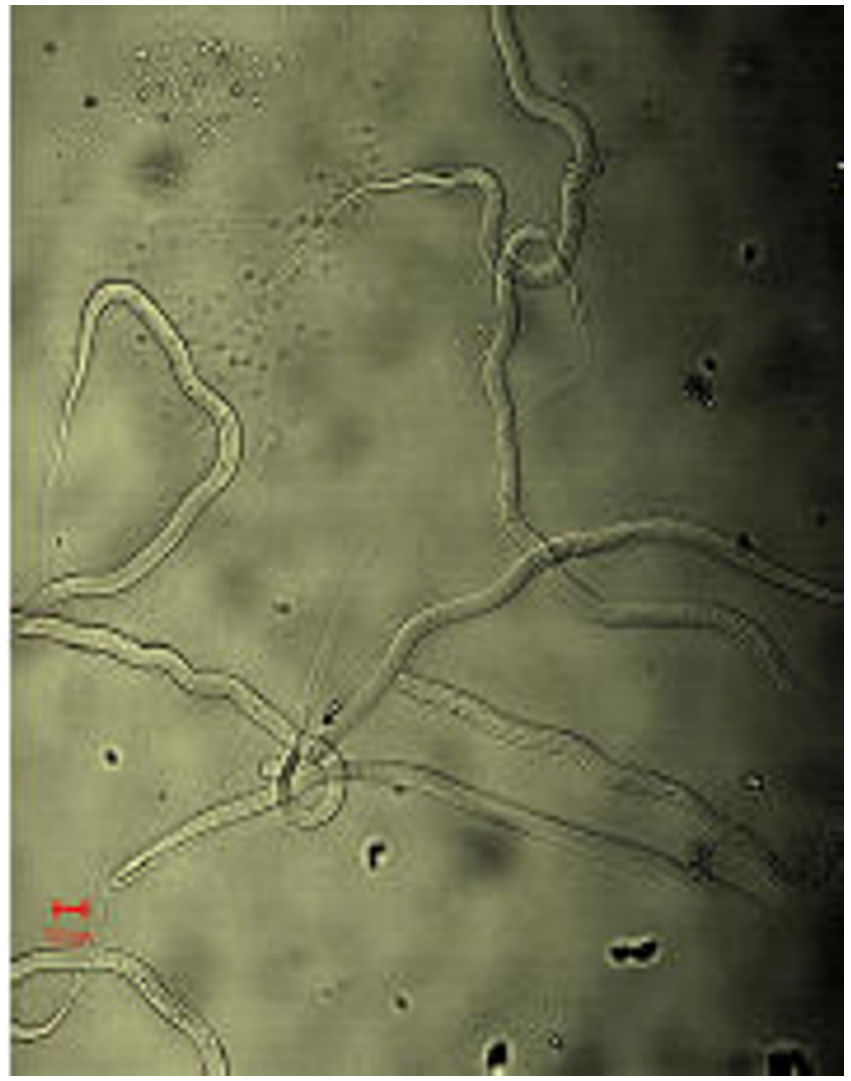

Figure 13

Sorted RI cells showing pure Mf.

\section{References}

I. Scott AL: Lymphatic - dwelling filariae. In Lymphatic filariasis Edited by: Nutman TB. Imperial College Press, London; 2000:5-39.

2. Pfarr KM, Fischer K, Hoerauf A: Involvement of Toll like receptor 4 in the embryogenesis of the rodent filaria Litomosoides sigmodontis. Med Microbiol Immunol 2003, 192:53-56.

3. Chirgwin SR, Coleman SU, Porthouse KH, Nowling JM, Punkosdy GA Klei TR: Removal of Wolbachia from Brugia pahangi is closely linked to worm death and fecundity but does not result in altered lymphatic lesion formation in Mongolian Gerbils(Meriones unguiculatus). Infection and Immunity 2003, 71:6986-6994.

4. Taylor MJ, Hoerauf A: Wolbachia bacteria of filarial nematodes. Parasitol Today 1999, 1 5:437-442.

5. Hoerauf A, Mand S, Adjei O, Fleischer B, Buttner DW: Depletion of Wolbachia endobacteria in Onchocerca volvulus by doxycycline and microfilaridermia after ivermectin treatment. The Lancet 200I, 357:14I5-1416.

6. Sahoo PK, Babu Geddam JJ, Satapathy AK, Mohanty MC, Ravindran B: Bancroftian filariasis: prevalence of antigenaemia and endemic normals in Orissa, India. Transactions of the Royal Society of Tropical Medicine and Hygiene 2000, 94:5I5-5I7.

7. Ravindran B, Satapathy AK, Sahoo PK, Mohanty MC: Protective immunity in human lymphatic filariasis: problems and prospects. Medical Microbiology and Immunology 2003, 192:41-468.

8. Lawrence RA: Immunity to filarial nematodes. Vet Parasitol 200I, I 2:33-44.

9. Triteeraprapab S, Richie TL, Tuan RS, Shepley KJ, Dinman JD, Neubert TA, Scott AL: Molecular cloning of a gene expressed during early embryonic development in Onchocerca volvulus. Mol Biochem Parasitol 1995, 69:161-71. 
10. Devaney E, Gillan V, Wheatley I, Jenson J, O'Conner R, Balmer P: Interleukin-4 influences the production of microfilariae in a mouse model of Brugia infection. Parasite Immunol 2002, 24:29-37.

II. Maizels RM, Blaxter M, Scott AL: Immunological genomics of Brugia malayi: filarial genes implicated in immune evasion and protective immunity. Parasite Immunology 200I, 23:327-344.

12. Ravindran B, Satapathy AK, Sahoo PK: Bancroftian filariasis-Differential reactivity of anti-sheath antibodies in microfilariae carriers. Parasite Immunology 1994, 16:32 I-323.

13. Gill MS, Olsen A, Sampayo JN, Lithgow GJ: An automated highthoroughput assay for survival of the nematode C.elegans. Free Radical Biology and Medicine 2003, 35:558-565.

Publish with Bio Med Central and every scientist can read your work free of charge

"BioMed Central will be the most significant development for disseminating the results of biomedical research in our lifetime. " Sir Paul Nurse, Cancer Research UK

Your research papers will be:

- available free of charge to the entire biomedical community

- peer reviewed and published immediately upon acceptance

- cited in PubMed and archived on PubMed Central

- yours - you keep the copyright

Submit your manuscript here:

http://www.biomedcentral.com/info/publishing_adv.asp
BiolMedcentral 